\title{
Unsuspected role for the T-cell leukemia protein SCL/tal-1 in vascular development
}

\author{
Jane E. Visvader, ${ }^{1,2}$ Yuko Fujiwara, ${ }^{1}$ and Stuart H. Orkin ${ }^{3}$ \\ Division of Hematology-Oncology, Children's Hospital and the Dana Farber Cancer Center, Department of Pediatrics, and \\ the Howard Hughes Medical Institute, Harvard M edical School, Boston, M assachusetts 02115 USA
}

\begin{abstract}
The transcription factor SCL/tal-1 is essential for blood cell development. Though it is also expressed in vascular endothelium, SCL has been considered dispensable for vessel formation. Through transgenic rescue of hematopoietic defects of $\mathrm{SCL}^{-1-}$ embryos and analysis of chimeras generated with SCL ${ }^{-1-}$ ES cells tagged with a transgene expressed in vascular endothelial cells, we show that SCL is essential for angiogenic remodeling of the yolk sac capillary network into complex vitelline vessels. These findings establish a role for SCL in embryonic angiogenesis and argue for critical functions in both embryonic blood and vascular cells, the descendents of the presumptive hemangioblast.
\end{abstract}

[Key Words: SCL/tal-1 gene; hematopoiesis; vascular devel opment; tie-2 gene]

Received October 24, 1997; revised version accepted December 12, 1997.

Blood cell formation and vasculogenesis initiate at $\sim$ E7.5 of mouse devel opment in the yolk sac blood islands. The close temporal and spatial relationship of hematopoiesis and vascular development is consistent with the existence of a postulated common progenitor, the hemangioblast (Pardanoud et al. 1989). The SCL/tal-1 gene [hereafter termed SCL (stem cell leukemia)], which was originally identified through its translocation in acute $\mathrm{T}$-cell Iymphoblastic leukemia (Begley et al. 1989; Finger et al. 1989; Chen et al . 1990), encodes a basic helix-loop-helix transcription factor that is expressed specifically in hematopoietic cells (Green et al. 1991; Visvader et al. 1991), vascular endothelium (Hwang et al. 1993; Kallianpur et al. 1994), and the developing brain (Green et al . 1992). Embryos lacking SCL fail to develop past E9.5 because of the absence of yolk sac erythropoiesis (Robb et al. 1995; Shivdasani et al. 1995) and SCL ${ }^{-1-}$ embryonic stem (ES) cells do not contribute to any hematopoietic lineages in chimeric mice (Porcher et al . 1996; Robb et al. 1996). Hence, SCL is believed to function either in programming commitment of ventral mesoderm to a hematopoi etic fate or in the generation of hematopoietic pluripotential stem cells. From the presence of vascular endothelial cells in $\mathrm{SCL}^{-1-}$ embryos it has been inferred that $\mathrm{SCL}$ is dispensable for vascular cell specification (Robb et al. 1995; Shivdasani et al. 1995).

To explore the potential involvement of SCL in nonhematopoietic pathways, we sought to rescue the hema-

\footnotetext{
${ }^{1}$ These authors contributed equally to this work.

2Present address: Walter and Eliza Hall Institute of Medical Research, Melbourne, Australia.

${ }^{3}$ Corresponding author.

E-MAIL orkin@rascal.med.harvard.edu; FAX (617) 355-7262.
}

topoietic defect in $\mathrm{SCL}^{-1-}$ embryos by introducing an SCL CDNA-transgene specifically expressed in the hematopoi etic compartment. By this approach, we uncovered an unsuspected but essential role for SCL in embryonic vessel development. By specifically tagging $\mathrm{SCL}^{-1-}$ ES cells with an endothelial-expressed lac Z gene, the fate of SCL ${ }^{-1-}$ endothelial cells was tracked in chimeras. This strategy provides evidence for a primary role for SCL in angiogenesis, a process entailing the proliferation and remodeling of pre-existing endothelial cells into a mature vascular network.

\section{Results}

Transgenic rescue of hematopoiesis

To rescue the hematopoi etic component of the SCL/ tal-1 knockout (Robb et al. 1995; Shivdasani et al. 1995), we first generated transgenic mice harboring SCL CDN A sequences under the control of regulatory sequences of the GATA-1 gene (McDevitt et al. 1997) (Fig. 1), as its hematopoietic expression profile mimics that of SCL (Visvader et al. 1991; Green et al. 1992). Of four founders, two independent lines of transgenic mice (GATA-1/ SCL-12 and GATA-1/SCL-52) expressed transgene-derived RNA at a level closely approximating that of the endogenous SCL mRNA in yolk sac (Fig. 2). $\mathrm{SCL}^{-1-} \mathrm{em}-$ bryos carrying the GATA-1/SCL transgene were generated by interbreeding $\mathrm{SCL}^{-1+} \mathrm{Tg}(\mathrm{GATA}-1 / \mathrm{SCL}-12$ or GATA-1/SCL-52) mice. Whereas $\mathrm{SCL}^{-1-}$ yolk sacs are devoid of any visible blood (Fig. 1C), hematopoiesis is substantially rescued in $\mathrm{SCL}^{-1-T g}$ yolk sacs, evident as diffuse red color (Fig. 1b). SCL ${ }^{-1-}$ Tg embryos, however, 

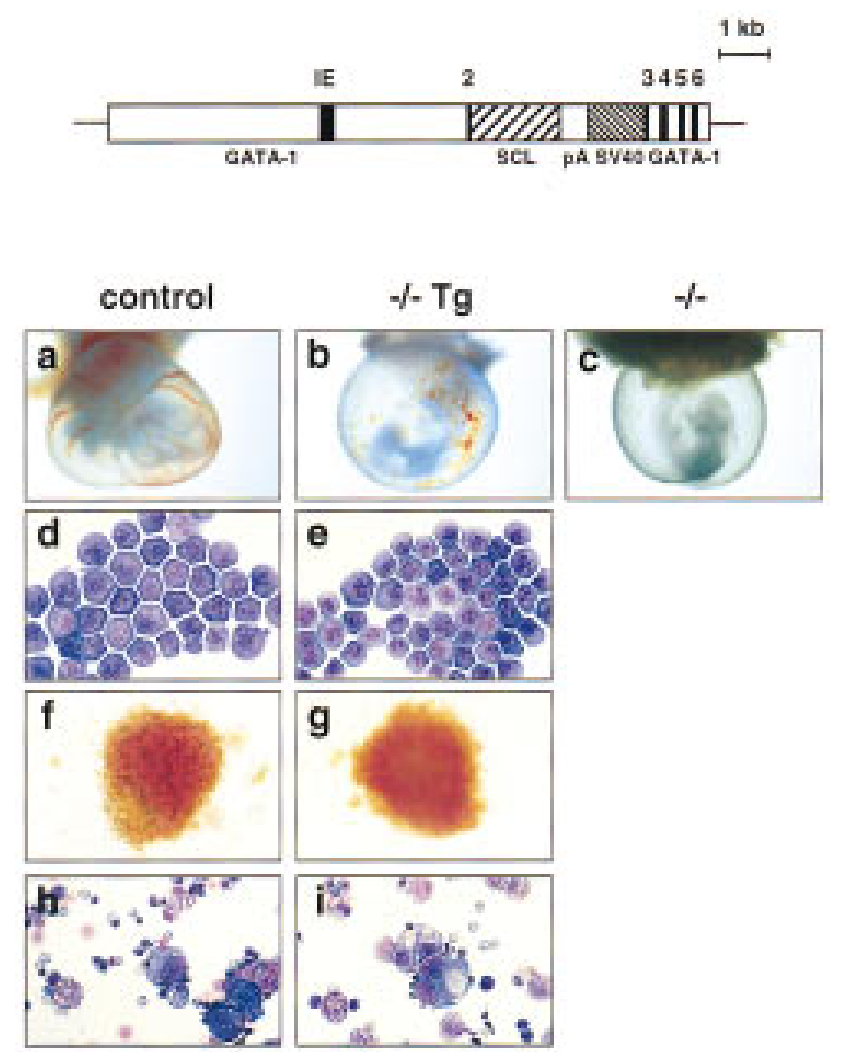

Figure 1. Rescue of hematopoiesis in $\mathrm{SCL}^{-1-}$ yolk sacs by introduction of the GATA-1/SCL transgene. (Top) Structure of the GATA-1/SCL transgenic construct: $7 \mathrm{~kb}$ of GATA-1 upstream sequence and $\sim 1.5 \mathrm{~kb}$ of sequence downstream of exon 3 flank the SCL CDNA. (IE) The first erythroid promoter of the murine GATA-1 gene. The rabbit gl obin poly(A) addition region and SV40 sequence provide polyadenylation signals and allow transgene detection. (Bottom) Phenotypes of wild-type (either $+1+$ or $+1 \rightarrow$ (a) SCL ${ }^{-1-} \mathrm{Tg}$ (b), and $\mathrm{SCL}^{-1-}$ (c) embryos with intact visceral yolk sacs (E9.5). Blood-filled vessels are visible in wildtype and $-1-\mathrm{Tg}$ yolk sacs. N ote the lack of branching vitelline vessels in the $-1-\mathrm{Tg}$ yolk sac. Original magnification, 18.75×(d,e) May-Grunwald-Giemsa-stained blood cells from E9.5 wild-type (d) and $\mathrm{SCL}^{-1-}$ (e) yolk sacs. Original magnification, 1000x (f, g) Day 7 BFU-E colonies generated by in vitro differentiation of wild-type or $\mathrm{SCL}^{-1-} \mathrm{Tg}$ yolk sac cells. Original magnification, 400x (h,i) May-Grunwald-Giemsa staining of mixed colonies at day 7 of differentiation from wild-type and $-1-\mathrm{Tg}$ yolk sacs. Mixed colonies were harvested and cytospun before staining. Original magnification, 320x

remained pal eand growth retarded. Like SC $\mathrm{L}^{-1-}$ embryos (Robb et al. 1995; Shivdasani et al. 1995), they failed to survive beyond E9.5 because of the vascular defects described below.

Blood cells present in the yolk sacs of $\mathrm{SCL}^{-1-} \mathrm{Tg} \mathrm{em}$ bryos appeared morphologically normal (Fig. 1d,e), indicating rescue of primitive erythropoiesis. Y olk sacs contained progenitors capable of generating multiple lineages, including erythroid, myeloid, mast, and megakaryocytic cells in hematopoietic colony assays (Shivdasani et al. 1995) (Fig. If-i). As colonies derived from yolk sacs at this stage are of the definitive (or adult) type, we conclude that definitive hematopoiesis is also restored by SCL expression. Rescue of multiple lineages by the GATA-1/SCL transgene suggests that the transcription factors GATA- 1 and SCL genes act at a similarly early point within the hematopoietic regulatory hierarchy, an inference consistent with their expression during embryogenesis (Silver and Palis 1997). Rescue, however, was quantitatively incomplete. The mean colony number per $\mathrm{SCL}^{-1-} \mathrm{Tg}$ yolk sac (based on four experiments) was 3.8-fold less for erythroid colonies/ BFU -E (37 \pm 8 for $-1-$ Tg v vs. $144 \pm 50$ for control cells, $+/+$ or $+/ \rightarrow$, 2.9-fold less for myeloid colonies (101 \pm 50 vs. $249 \pm 110)$ and 4.5 -fold less for mixed colonies ( $41 \pm 7$ vs. $186 \pm 30$ ). The reduced potential of the $\mathrm{SCL}^{-1-} \mathrm{Tg}$ yolk sac cells to form erythroid colonies was also reflected in their relative levels of $\zeta, \alpha$, and $\beta$ hl globin RNA (Fig. 2; data not shown). The inability to achieve full rescue may be attributable to improper timing or regulation of SCL transgene expression imposed by the GATA-1 control sequences.

\section{$\mathrm{SCL}^{-1-}$ and $\mathrm{SCL}^{-1-} \mathrm{Tg}$ yolk sacs lack vitelline vessels}

The pattern of vasculature within the $\mathrm{SCL}^{-1-} \mathrm{Tg}$ yolk sacs was striking (Fig. 1b). Rather than the distinctive network of branching vitelline vessels visual ized in normal embryos (Fig. 1a), a disorganized array of capillaries was observed, a finding corroborated by wholemount staining with anti-PECAM antibodies, a specific marker of differentiated endothelial cells (Baldwin et al. 1994). The absence of vitelline vessels, but presence of an interconnecting network of smaller vessels, was al so noted for $\mathrm{SCL}^{-1-}$ yolk sacs (Fig. 3a-C). Individual endothelial cells of control and $\mathrm{SCL}^{-1-}$ yolk sacs, however, stained similarly for PECAM (Fig. 3d-f) and CD34 (Fig. 3g,h), another marker of differentiated endothelial cells (Baumhueter et al . 1994). Both the endothelial and endodermal cell layers, as well as the smooth muscle/ pericytes that constitute the lining of vessels, appeared intact by histol ogical analysis (Fig. 3i, j) and el ectron microscopy (data not shown). Taken together, these data indicate that specification of vascular cells proceeds normally in the absence of SCL but that angi ogenesis is defective, either as a primary or secondary consequence of the deficiency. As to be expected, this defect persists in the $\mathrm{SCL}^{-1-} \mathrm{Tg}$ embryos, as regulatory sequences of the GATA-1-basedtransgene are inactive in vascular cells. Histological analysis of the $\mathrm{SCL}^{-1-}$ and $\mathrm{SCL}^{-1-} \mathrm{Tg}$ embryos proper suggested that the vascul ature may be more disorganized than in wild-type littermates, but severe growth retardation and necrosis by E9.5 precluded a detailed analysis. We speculate that the $\mathrm{SCL}^{-1-}$-Tg embryos die by E9.5 due to the absence of connecting blood vessels between the yolk sac and embryo.

Endothelial receptor tyrosine kinases are expressed in $\mathrm{SCL}^{-1-}$ yolk sacs

Several genes are essential for the development and in- 

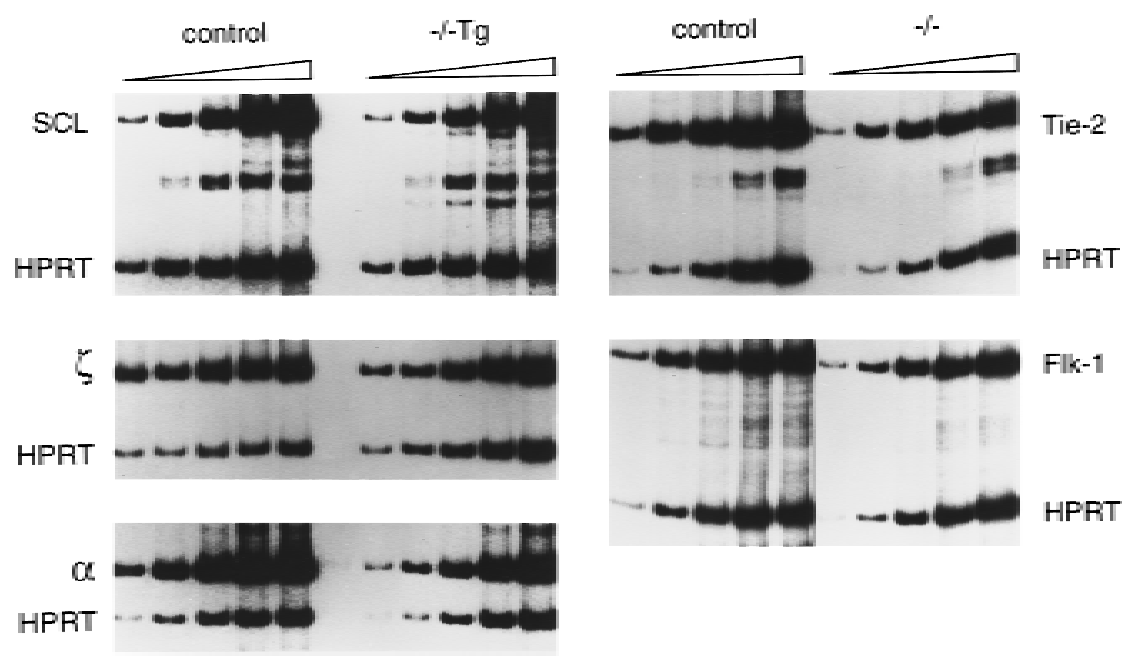

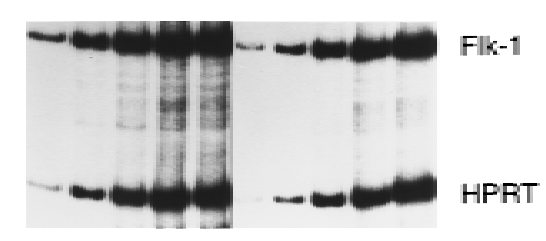

Figure 2. RNA expression of $S C L$ and globins in $\mathrm{SCL}^{-1-} \mathrm{Tg}$ yolk sacs and of receptor tyrosine kinases in $\mathrm{SCL}^{-1-}$ cells. RT-PCR analyses were performed with RNAs obtained from single yolk sacs at E9.5. Samples for SCL and the globins were amplified for six cycles in the presence of HPRT primers, before addition of SCL, or $\alpha$ or $\zeta$ globin primers. Aliquots were then removed after an additional $16,18,20,22$, and 24 cycles. Levels of globin transcripts were 1.3- to 3.1-fold lower in SCL ${ }^{-1-}$ Tg yolk sacs compared to that in controls. PCR reactions for Tie-2 and Flk-1 were performed for four cycles prior to the addition of HPRT primers and amplified for a further $18,20,22,24$, and 26 cycles. tegrity of the yolk sac vascular system (Risau 1997). These include receptor tyrosine kinases and their ligands. The transcriptional status of several of these
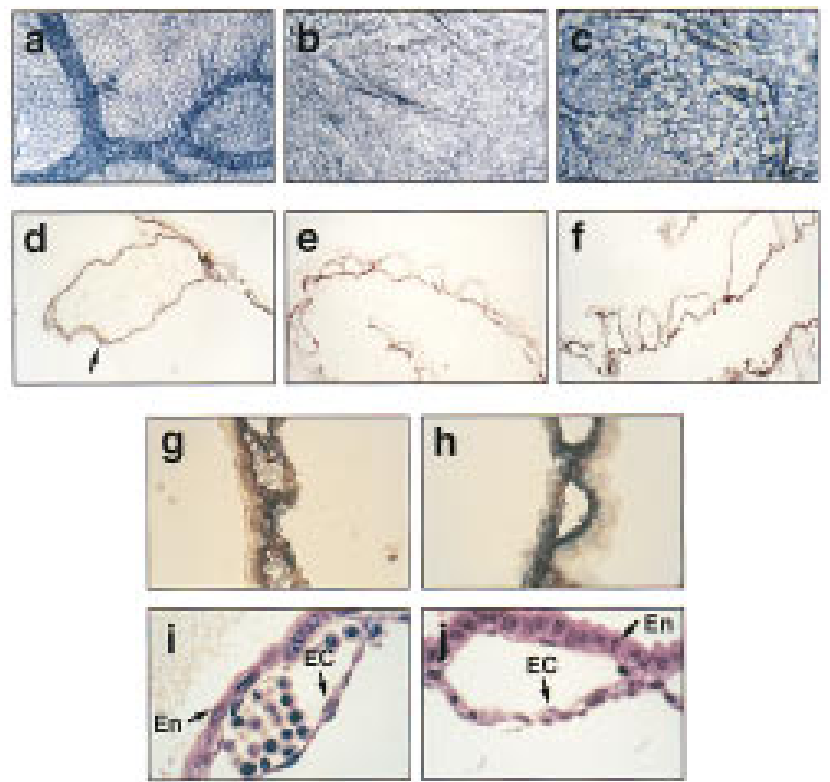

Figure 3. Defective angiogenesis in $\mathrm{SCL}^{-1-}$ and $\mathrm{SCL}^{-1-}$ Tgyolk sacs. (a-c) Whole-mount staining with anti-PECAM antibody of E9.5 yolk sacs derived from wild-type, $\mathrm{SCL}^{-1-}$ and ${ }^{-1-} \mathrm{Tg}$ embryos shows the presence of capillaries and absence of vitelline vessels in both $\mathrm{SCL}^{-1-}$ and $\mathrm{SCL}^{-1-} \mathrm{Tg}$ yolk sacs. Original magnification, $18.75 \times(d-f)$ Sections of anti-PECAM whole-mountstained yolk sacs from $a, b$, and $c$, revealing specific staining of endothelial cells. The arrow designates a vitelline vessel, only observed in control yolk sacs. Original magnification, 400x $(g, h)$ Sections of wild-type and mutant $(-t-$ yolk sac stained with anti-CD34, a marker of endothelium and early hematopoietic cells. Original magnification, $1000 \times(i, j)$ Hematoxylin and eosin staining of wild-type and $\mathrm{SCL}^{-1-}$ yolk sac sections. (En) extraembryonic endoderm; (EC) endothelial cell. Original magnification, 1000x genes was evaluated by RT-PCR to search for potential SCL target genes in endothelial cells (Fig. 2; data not shown). The expression of the endothelial RTKs, Flk-1, Tie-1, and Flt-4, in SCL ${ }^{-1-}$ yolk sacs was comparable to that observed in normal yolk sacs, although Tie-2 and FIt-1 RNA levels appeared to be diminished slightly (about two fold). These findings suggest that the number of endothelial cells in mutant yolk sacs is approximately the same as in wild type. The levels of TEL (Wang et al. 1997) and $\mathrm{G} \alpha_{13}$ (Offermanns et al. 1997) transcripts al so appeared normal. Hence, none of the above genes are likely to be essential early targets of the SCL transcription factor in vascular endothelium.

\section{A berrant vasculature in $\mathrm{SCL}^{-1-} / \mathrm{ROSA}$ chimeras}

Although it remained formal ly plausi ble that the angiogenic defect was merely secondary to the absence of blood in $\mathrm{SCL}^{-1-}$ embryos, it seemed improbable for at least two reasons. (1)The defect was evident in yolk sacs displaying substantial hematopoietic rescue; and (2) other hematopoiesis-defective embryos, such as those lacking GATA-1 or GATA-2 (Shivdasani and Orkin 1996), have normal vasculature, despite a marked decrease in blood volume. To distinguish between primary or secondary effects of SCL loss on angiogenesis, we generated two different types of chimeras. Because ES cells often display a marked bias in tissue distribution following blastocyst injection, we produced chimeras with either marked ES cells or blastocysts to follow the fate of donor $\mathrm{SCL}^{-1-} \mathrm{ES}$ cells in devel oping yolk sacs.

$\mathrm{SCL}^{-1-}$ ES cells were first injected into blastocysts of $\beta$-galactosidase (lacZ)-expressing ROSA 26 mice (Zambrowicz et al. 1997). The degree of chimerism was estimated by lacZ staining of sections through E9.5 chimeric yolk sacs (data not shown). Of particular note, we observed that the level of contribution by the $\mathrm{SCL}^{-1-}$ cells correlated with the vascular, as well as the hematopoietic, phenotypes of the yolk sacs. Typical phenotypes of $\mathrm{SCL}^{-1-} / \mathrm{ROSA}$ chimeras are shown in Figure 
$4 a-c$. Y olk sacs estimated to be $\sim 80 \%$ chimeric (Fig. 4a) were pale and exhibited a patchy, disorganized network of capillaries lacking vitel line vessels, thereby recapitulating the $\mathrm{SCL}^{-1-} \mathrm{Tg}$ vascular phenotype. Although a more well-developed vascular network was evident in yolk sacs exhibiting $20 \%$ chimerism (Fig. $4 \mathrm{~b}$ ), the vessels were uniformly dilated with no clear distinction between large and small vessels. Conversely, vitelline vessels were readily visual ized in low chimeric $(<5 \%)$ yolk sacs (Fig. 4C). The analysis of SCL $\mathrm{L}^{-1-} / \mathrm{ROSA}$ chimeras, therefore, suggests that the presence of $\mathrm{SCL}^{-1-}$ cells in the developing yolk sac leads to abnormal vessel formation.

Tagged $\mathrm{SCL}^{-1-}$ endothelial cells do not contribute to large vessels in chimeras

To investigate a primary rol e for $S C L$ in angiogenesis, we generated a second type of chimera using wild-type blastocysts and $\mathrm{SCL}^{-1-}$ ES cells harboring a Tie-2-lacZ reporter gene (Schlaeger et al. 1997) (Fig. 4, bottom). The Tie-2-lacZ transgene directs uniform and high-level expression to all endothelial cells. In control experiments we demonstrated that $\mathrm{SCL}^{-1+/ T i e-2-l a c Z}$ cells readily contributed to both small and large vessels of the developing yolk sac vasculature (Fig. 4d,e; note solid arrow in

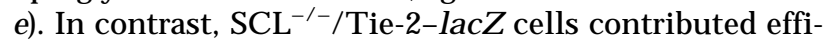
ciently to small capillaries but were not observed in vitelline vessels of multiple chimeras of varying extents generated from three different marked $\mathrm{SCL}^{-1-} \mathrm{ES}$ cell clones (Fig. 4f-k; note open arrow in i). In addition, the aberrant vascular architecture observed in whole yolk sacs containing a high proportion of $\mathrm{SCL}^{-1-}$-derived endothelial cells paralleled the phenotypes observed for $\mathrm{SCL}^{-1-}$ and $\mathrm{SCL}^{-1-} \mathrm{Tg}$ embryos (Fig. 4f,g), in which only small capillaries were detectable. These data provide direct evidence for an intrinsic defect in the capacity of $\mathrm{SCL}^{-1-}$ endothelial cells to participate in the formation of large vessels during the process of angiogenesis.

\section{Discussion}

Our goal in the studies reported here was to identify nonhematopoietic roles of SCL in development. To this end, we used cell-specific transgenic rescue to reveal functions obscured by early embryonic lethality of a knockout embryo. The relatively efficient rescue of yolk sac hematopoiesis by a transgene driven by GATA-1 regulatory sequences suggests that GATA-1 and SCL act at a similarly early point within the hematopoietic regulatory hierarchy. Furthermore, GATA-1 gene-based constructs may be useful in the rescue of hematopoietic defects of other knockout embryos. Transgenic rescue provided initial evidence for a vascul ar defect in the absence of $\mathrm{SCL}$, a finding corroborated and extended by chimera studies, particularly employing $\mathrm{SCL}^{-1-}$ ES cells tagged with a Tie-2-lacZ reporter gene.
Figure 4. $\mathrm{SCL}^{-1-}$ cells contribute to the endothelium of small but not large vessels in chimeric yolk sacs. The contribution of SCL-deficient cells to the endothelium of E9.5 chimeras was analyzed by $\beta$-galactosidase whole-mount staining. (a-c) $\beta-G a-$ lactosidase-stained yolk sacs derived from $\mathrm{SCL}^{-1-}$ /ROSA chimeras. The approximate degree of chimerism is shown bel ow each. $\mathrm{N}$ ote the disorganized vascular architecture in the higher percentage chimeras, a and b. Original magnification, $22.5 \times(f-k)$ Sections of stained yolk sacs of chimeric embryos derived from Tie-2-lacZ-marked $\mathrm{SCL}^{+1-}$ or $\mathrm{SCL}^{-1-} \mathrm{ES}$ cells. (d,e) $\mathrm{SCL}^{+1-}$ cells contribute uniformly to capillaries and vitelline vessels in chimeric yolk sacs. $\mathrm{N}$ ote the contribution of lacZ-positive cells to large vessels, as indicated by the solid arrow in e. (f-k) In contrast, $\mathrm{SCL}^{-1-}$ derived endothelial cells were not detectable lining the lumens of vitelline vessels, as highlighted by the open arrow in i. N ote that the $\mathrm{SCL}^{-1-} \mathrm{ES}$ cells contribute efficiently to capillaries. Original magnification, 400x, except for a and f, which were 200x The structure of the Tie2-lacZ transgene (kindly provided by T. Sato, University of Texas Southwestern Medical School, Dallas) is shown in the bottom panel.
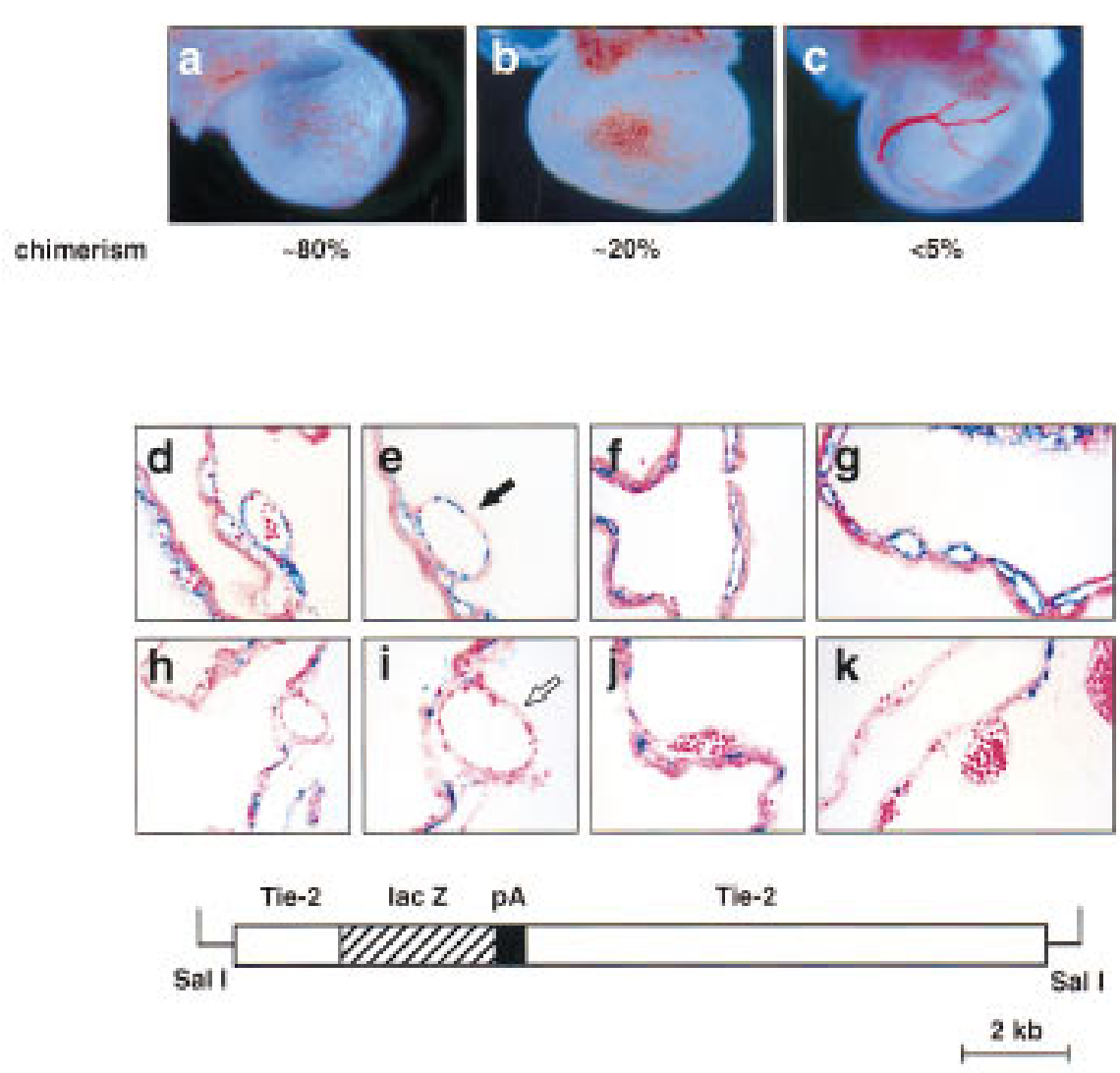
Role for SCL in vascular development

Blood vessels develop by two distinct processes, vasculogenesis and angiogenesis. Vasculogenesis involves the differentiation of endothelial cells from their mesodermal precursors and the subsequent assembly into a primary capillary pl exus. During angi ogenesis, these primary vessels are remodeled into a larger, more complex network. Although SCL appears to be dispensable for initial specification and proliferation of endothelial cells, the present work demonstrates that it is required for formation of branching vitelline vessels from a primary vascular plexus. Furthermore, the vascular defects associated with loss of SCL appear to be endothelial-specific, as shown by the Tie-2-lacZ transgene experiments and ultrastructure analysis indicating that the mesenchyme/ smooth muscle layer is intact (data not shown).

Several genes encoding receptor tyrosine kinases (RTKs), such as Flk-1 (Shalaby et al. 1995, 1997), Flt-1 (Fong et al. 1995), Tie-1 (Puri et al . 1995; Sato et al. 1995), and Tie-2 (Dumont et al. 1994; Sato et al. 1995); and the ligands, such as vascular endothelial growth factor (VEGF) (Carmeliet et al. 1996a; Ferrara et al. 1996), angiopoi etin-1 (Ang-1) (Suri et al. 1996), and tissue factor (TF) (Carmeliet et al. 1996b), are important for proper yolk sac vascular development (Risau 1997). Targeted disruption of these genes has provided insights into intracellular signal ing mechanisms that govern blood vessel formation. However, none of these genes, nor the transcription factor TEL (Wang et al. 1997) or the G protein $\mathrm{G}_{13}$ (Offermanns et al. 1997), appear to be early targets of SCL, as shown by RT-PCR analysis.

The $\mathrm{SCL}^{-1-}$ vascular defect most closely resembles that of embryos lacking Tie-2 (Dumont et al. 1994; Sato et al. 1995). Tie-2 has direct effects on the endothelium but has al so been implicated in angi ogenesis by virtue of an activating mutation that causes vascular dysmorphogenesis (Vikkula et al. 1996). Although targeted disruption of several other genes (Risau 1997), such as Ang-1, VEGF, TF, and aryl hydrocarbon receptor nuclear translocator (ARNT) (Mal tepe et al. 1997), leads to similar yolk sac phenotypes, these seem to reflect aberrant interactions/signaling between the endothelium and surrounding mesenchymal cells. In contrast, SCL is required in a cell autonomous fashion for remodeling of endothelial cells into a mature vascular network.

Taken together with earlier studies, our findings establish a dual function for SCL in hematopoiesis and vascular devel opment (Fig. 5). The cl ose rel ationship between hematopoiesis and vasculogenesis in the developing yolk sac blood islands is consistent with the existence of a common progenitor, the hemangioblast (Pardanoud et al. 1989). The requirement for the receptor Flk-1 in both hematopoi esis and vascul ogenesis (Shal aby et al. 1995, 1997) is compatible with this model. Although our current data do not bear directly on the existence of the hemangioblast, they do establish SCL as having a unique regulatory function, positioned at the interface between blood and vascular development. Identifying critical target genes for SCL in vascular endothelial cells should elucidate novel angiogenic pathways and their possible relationship to those al ready defined.

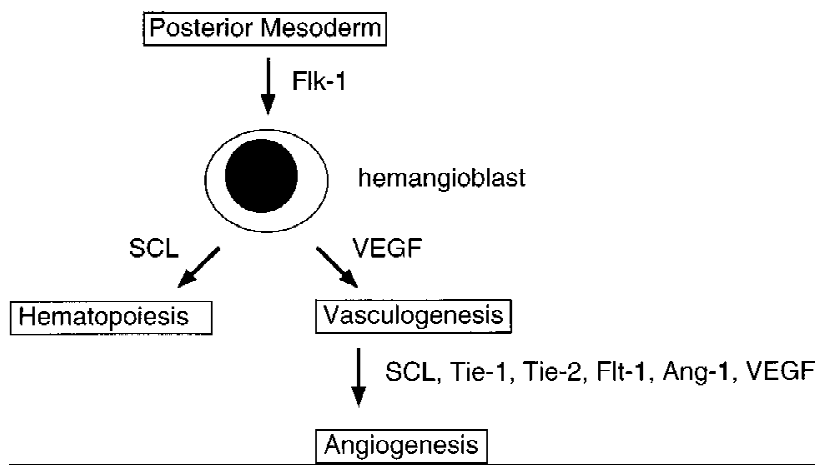

Figure 5. Dual function for $\mathrm{SCL}$ in the developing embryo. SCL has distinct roles in regulating angiogenesis (sprouting and remodeling of the vasculature) and early hematopoietic events (prior to commitment of progenitors to different lineages). The sites of action of rel evant genes in blood vessel development, as determined by targeted disruption, are shown. (Ang-1) Angiopoietin-1. The existence of the bi potential hemangioblast is hypothetical.

\section{Materials and methods}

Constructs and transgenic mice production

A 1.4-kb murine SCL CDN A fragment was linked to the rabbit $\beta$-globin polyadenylation region and a 900-bp fragment spanning the SV40 early intronic region and polyadenylation signal (Lindeman et al. 1995), which also allow transgene detection, before insertion into a vector containing regulatory sequences derived from the murine GATA-1 gene (M cDevitt et al. 1997). The final insert, released by Sall digestion, was introduced by pronuclear injection into fertilized eggs derived from a CD1 strain (Charles River). Southern blot analysis with the 900-bp SV40 fragment was used to identify transgenics; progeny tail DN A was subsequently typed by PCR using SV 40 primers. Two independent transgenic lines were established and were crossed with SCL heterozygous mice $(129 \times \mathrm{C} 57 \mathrm{BL} / 6 \mathrm{~N})$ (Shivdasani et al. 1995) to produce $\mathrm{SCL}^{+-}-\mathrm{Tg}$ strains, which were then mated to produce $\mathrm{SCL}^{-1-} \mathrm{Tg}$ embryos.

A 15-kb Tie-2-lacZ insert was isolated from pT 2HlacZpA 11.7 (Schlaeger et al. 1997) by Sall digestion and ligated to a fivefold molar excess of Xhol-digested PGK-puromycin cassette $(2.1 \mathrm{~kb})$ for $2 \mathrm{hr}$ at $16^{\circ} \mathrm{C}$ before final purification. The DNA was electroporated into either $\mathrm{SCL}^{-1-}$ or $\mathrm{SCL}^{+-} \mathrm{J} 1 \mathrm{ES}$ cells; the $\mathrm{SCL}^{+-}$ had also undergone two rounds of $\mathrm{G} 418$ selection to provide a control line (Porcher et al. 1996). Puromycin-resistant clones were typed by Southern blot analysis and PCR for detection of the lacZ insert.

\section{Yolk sac progenitor assay}

These were performed essentially as described (Shivdasani et al. 1995). The yiel $d$ for each collagenase-treated yolk sac (E9.5) was $1 \times 10^{4}$ to $5 \times 10^{4} / \mathrm{ml}$. The disaggregated cells were plated in $\alpha$-minimal essential medium supplemented with $\alpha$ methylcellulose, $30 \% \mathrm{FCS}, 1 \% \mathrm{BSA}$, and $2 \mathrm{U} / \mathrm{ml}$ of erythropoietin, 50 $\mathrm{ng} / \mathrm{ml}$ of recombinant c-kit ligand, $5 \mathrm{ng} / \mathrm{ml}$ of IL- 11 , and 10 $\mathrm{ng} / \mathrm{ml}$ of IL-3.

\section{Semiquantitative RT-PCR}

RN As were isolated from individual E9.5 yolk sacs and genomic DNA from the embryos used to confirm their genotype. RT- 
PCR was performed as described (Weiss et al. 1994), using two sets of primers, one representing the specific gene and the other HPRT. In the case of SCL, $10 \%$ dimethylsulfoxide was included in the reactions. The sequence of the oligonucleotide primers has been described el sewhere; SCL (Porcher et al. 1996), HPRT and globins (Weiss et al. 1994), and Tel, Flk-1, Tie-2, and other RTKs (Carmeliet et al. 1996). Relative quantitations versus HPRT were performed using a Phosphorlmager (M olecular Dynamics). Control experiments without reverse transcriptase in the CDN A synthesis reactions did not show these specific PCR products.

\section{Immunohistochemistry and histology}

Whole-mount immunohistochemistry using anti-PECAM monoclonal antibody M EC 13.3 (Pharmingen) was performed essentially as described (Schlaeger et al. 1995). The stained yolk sacs were postfixed in $4 \%$ paraformal dehyde, embedded in paraffin wax, and sectioned at $8 \mu \mathrm{m}$. Affinity purified polyclonal antiCD34 antibody (Baumhueter et al. 1994) was used to stain 10$\mu \mathrm{m}$ cryosections of dissected E9.5 embryos and yolk sacs that had been previously fixed with $4 \%$ paraformal dehyde. Ten-micrometer sections were used for immunohistochemical staining; alkaline phosphatase staining was used for antibody detection.

\section{Generation and analysis of chimeras}

Chimeras were generated by blastocyst injection as described (Hogan et al. 1994). Mice carrying the ROSA 26 gene trap integration (Zambrowicz et al. 1997) were obtained from Jackson Laboratories [TgR(ROSA 26)RSor strain]. For the ROSA chimera experiments, blastocysts were collected from matings between homozygous ROSA 26 and C57BL/6N T acfBR (Taconic) mice. A maximum of 16-18 ES cells were injected into the blastocyst cavity. Chimeric percentages were estimated by $\beta$-gal actosi dase staining of yolk sacs. For Tie-2-lacZ transgenic ES cell experiments, blastocysts were collected from matings between C57BL/6N TacfBRs (Taconic). To produce relatively low chimeric embryos, the number of ES cells injected into the blastocyst cavity was, on average, 8-10. Following transfer into pseudopregnant foster females, the embryos were recovered at day 9.5 or 10.5 of development. Embryos were fixed and processed for $\beta$-galactosidase as described previously (Hogan et al. 1994). After staining, embryos and their yolk sacs were postfixed with $4 \%$ paraformal dehyde and embedded in paraffin wax. Samples were sectioned at $8 \mu \mathrm{m}$ and counterstained with neutral red.

\section{Acknowledgments}

We are grateful to Drs. M. McDevitt and T. Sato for providing vectors containing the GATA-1 regulatory sequences and Tie2/lacZ cassette, respectively, and Dr. L. Laskey for providing CD34 antibody. We thank Carol Browne and Kerrianne Cunniff for technical assistance. J.V. was the recipient of a Union Internationale Centre de Cancer (UICC)/American Cancer Society Senior Fellowship. S.H.O. is an Investigator of the Howard Hughes Medical Institute.

The publication costs of this article were defrayed in part by payment of page charges. This article must therefore be hereby marked "advertisement" in accordance with 18 USC section 1734 solely to indicate this fact.

\section{References}

Baldwin, H., H. Shen, H. Yan, H. DeLisser, A. Chung, C. Mickanin, T. Trask, N. Kirschbaum, P. N ewman, S. Albelda et al. 1994. Platelet endothelial cell adhesion molecule-1 (PECAM-1/CD31): alternatively spliced, functionally distinct isoforms expressed during mammalian cardiovascular development. Development 120: 2539-2553.

Baumhueter, S., N . Dybdal, C. Kyle, and L. Laskey. 1994. GlobuIar vascular expression of murine CD34, a sialo mucin-like endothelial lingand for L-selectin. Blood 84: 2554-2565.

Begley, C., P. A plan, S. Denning, B. Haynes, T. Waldmann, and I. Kirsch. 1989. The gene SCL is expressed during early he matopoiesis and encodes a differentiation-related DNAbinding motif. Proc. Natl Acad. Sci. 86: 10128-10132.

Carmel iet, P., V. Ferreira, G. Breier, S. Poll efeyt, L. Kieckens, M. Gertsenstein, M. Fahrig, A. Vandenhoeck, K. Harpal, C. Eberhardt, C. Declercq, J. Pawling, L. Moons, D. Collen, W. Risau, and A. N agy. 1996a. A bnormal blood vessel development and lethality in embryos lacking a single VEGF allele. Nature 380: 435-439.

Carmeliet, P., N. Mackman, L. M oons, T. Luther, P. Gressens, I. Van Vlaenderen, H. Demunck, M. Kasper, G. Breier, P. Evrard, M. Müller, W. Risau, T. Edgington, and D. Collen. 1996b. Role of tissue factor in embryonic blood vessel development. Nature 383: 73-75.

Chen, Q., J.-T. Cheng, L.-H. Tsai, N. Schnei der, G. Buchanan, A. Carroll, W. Crist, B. Ozanne, M.J. Siciliano, and R. Baer. 1990. The tal gene undergoes chromosome translocation in $T$ cell leukemia and potentially encodes a helix-loop-helix protein. EMBO J. 9: 415-424.

Dumont, D., J.G. Gradwohl, G.-H. Fong, M. Puri, M. Gertsenstein, A. Auerbach, and M.L. Breitman. 1994. Dominantnegative and targeted null mutations in the endothelial receptor tyrosine kinase, tek, reveal a critical role in vasculogenesis of the embryo. Genes \& Dev. 8: 1897-1909.

Ferrara, N., K. Carver-M oore, H. Chen, M. Dowd, L. Lu, K.S. O'Shea, L. Powell-Braxton, K.J. Hillan, and M. M oore. 1996. Heterozygous embryonic lethality induced by targeted inactivation of the VEGF gene. Nature 380: 439-442.

Finger, L.R., J. Kagan, G. Christopher, J. Kurtzberg, M.S. Hershfield, P.C. N owell, and C.M. Croce. 1989. Involvement of the TCL5 gene on human chromosome 1 in T cell leukemia and melanoma. Proc. Natl Acad. Sci. 86: 5039-5043.

Fong, G.-H., J. Rossant, M. Gertsenstein, and M.L. Breitman. 1995. Role of the Flt-receptor tyrosine kinase in regulating the assembly of vascular endothelium. Nature 376: 66-70.

Green, A.R., E. Salvaris, and C.G. Begley. 1991. Erythroid expression of the helix-loop-helix gene SCL. Oncogene 6: 475479.

Green, A.R., T. Lints, J. Visvader, R. Harvey, and C.G. Begley. 1992. SCL is coexpressed with GATA-1 in haemopoietic cells but is also expressed in developing brain. Oncogene 7: 653-660.

Hogan, B., R. Beddington, F. Constantini, and E. Lacy. 1994. Manipulating the mouse embryo: A laboratory manual. Cold Spring Harbor Laboratory Press, Cold Spring Harbor, NY.

Hwang, L.-Y., M. Siegel man, L. Davis, N . Oppenhei mer-M arks, and R. Baer. 1993. Expression of the TAL1 proto-oncogene in cultured endothelial cells and blood vessels of the spleen. Oncogene 8: 3043-3046.

Kallianpur, A.R., J.E. Jordan, and S.J. Brandt. 1994. The SCL/ TAL-1 gene is expressed in progenitors of both the hematopoietic and vascular systems during embryogenesis. Blood 83: 1200-1208.

Lindeman, G.J., A.W. Harris, M.L. Bath, R.N. Eisenman, and J.M. Adams. 1995. Overexpressed max is not oncogenic and attenuates myc-induced lymphoproliferation and lymphomagenesis in transgenic mice. Oncogene 10: 1013-1017. 
Maltepe, E., J.V. Schmidt, D. Baunoch, C.A. Bradfield, and M.C. Simon. 1997. Abnormal angiogenesis and responses to glucose and oxygen deprivation in mice lacking the protein ARNT. Nature 386: 403-407.

McDevitt, M.A., Y. Fujiwara, R.A. Shivdasani, and S.H. Orkin. 1997. An upstream, DNase I hypersensitive region of the hematopoietic-expressed transcription factor GATA-1 gene confers developmental specificity in transgenic mice. Proc. Natl Acad. Sci. 94: 7976-7981.

Offermanns, S., V. M ancino, J.-P. Revel, and M.I. Simon. 1997. Vascular system defects and impaired cell chemokinesis as a result of $\mathrm{G}_{\alpha_{13}}$ deficiency. Science 275: 533-536.

Pardanoud, L., F. Y assine, and F. Dieterlen-Lievre. 1989. Relationship between vasculogenesis, angiogenesis, and haemopoiesis during avian ontogeny. Development 105: 473-485.

Porcher, C., W. Swat, K. Rockwell, Y. Fujiwara, F.W. Alt, and S.H. Orkin. 1996. The T cell leukemia oncoprotein SCL/ tal-1 is essential for development of all hematopoietic lineages. Cell 86: 47-57.

Puri, M.C., J. Rossant, K. Alitalo, A. Bernstein, and J. Partanen. 1995. The receptor tyrosine kinase TIE is required for integrity and survival of vascular endothelial cells. EMBO J. 14: 5884-5891.

Risau, W. 1997. Mechanisms of angiogenesis. Nature 386: 671674.

Robb, L., I. Lyons, R. Li, L. Hartley, F. Köntgen, R.P. Harvey, D. Metcalf, and C.G. Begley. 1995. Absence of yolk sac hematopoiesis from mice with a targeted disruption of the scl gene. Proc. Natl Acad. Sci. 92: 7075-7079.

Robb, L., N. Elwood, A.G. Elefanty, F. Köntgen, R. Li, D. Barnett, and C.G. Begley. 1996. The scl gene product is required for the generation of all hematopoietic lineages in the adult mouse. EMBO J. 15: 4123-4129.

Sato, T.N., Y. Tozawa, U. Deutsch, K. Wolburg-Buchholz, Y. Fujiwara, M. Gendron-M aguire, T. Gridley, H. Wolburg, W. Risau, and Y. Qin. 1995. Distinct roles of the receptor tyrosine kinases Tie-1 and Tie-2 in blood vessel formation. Nature 376: 70-74.

Schlaeger, T.M., S. Bartunkova, J.A. Lawitts, G. Teichmann, W. Risau, U. Deutsch, and T.N. Sato. 1997. Uniform vascularendothelial-cell-specific gene expression in both embyronic and adult transgenic mice. Proc. Natl. Acad. Sci. 94: 30583063.

Schlaeger, T.M., Y. Qin, Y. Fujiwara, J. M agram, and T.N. Sato. 1995. Vascular endothelial cell lineage-specific promoter in transgenic mice. Development 121: 1089-1098.

Shalaby, F., J. Rossant, T. Yamaguchi, M. Gertsenstein, X.-F. Wu, M. Breitman, and A.C. Schuch. 1995. Failure of bloodisland formation and vasculogenesis in Flk-1 deficient mice. Nature 376: 62-66.

Shalaby, F., J. Ho, W.L. Stanford, K.-D. Fischer, A.C. Schuch, L. Schwartz, A. Bernstein, and J. Rossant. 1997. A requirement for Flk1 in primitive and definitive hematopoiesis and vasculogenesis. Cell 89: 981-990.

Shivdasani, R.A., and S.H. Orkin. 1996. The transcriptional control of hematopoiesis. Blood 87: 4025-4039.

Shivdasani, R.A., E.L. M ayer, and S.H. Orkin. 1995. Absence of blood formation in mice lacking the $T$ cell leukaemia protein tal-1/SCL. Nature 373: 432-434.

Silver, L., and J. Palis. 1997. Initiation of murine embryonic erythropoiesis: A spatial analysis. Blood 89: 1154-1164.

Suri, C., P.F. Jones, S. Patan, S. Bartunkova, P.C. M aisonpierre, S. Davis, T.N. Sato, and G.D. Yancopoulos. 1996. Requisite role of angiopoietin-1, a ligand for the TIE2 receptor, during embryonic angiogenesis. Cell 87: 1171-1180.

Vikkula, M., L.M. Boon, K.L. Carraway III, J.T. Calvert, A.J.
Kiamonti, B. Goumnerov, K.A. Pasyk, D.A. Marchuk, M.L. Warman, L.C. Cantley, J.B. Mulliken, and B.R. Olsen. 1996. Vascular dysmorphogenesis caused by an activating mutation in the receptor tyrosine kinase TIE2. Cell 87: 11811190.

Visvader, J., C.G. Begley, and J.M. Adams. 1991. Differential expression of the LYL, SCL and E2A helix-loop-helix genes within the hemopoietic system. Oncogene 6: 187-194.

Wang, L.C., F. Kuo, Y. Fuji wara, D.G. Gilliland, T.R. Golub, and S.H Orkin. 1997. Yolk sac angiogenic defect and intra-embryonic apoptosis in mice lacking the ETs-related factor TEL. EMBO J. 16: 4374-4383.

Weiss, M.J., G. Keller, and S.H. Orkin. 1994. N ovel insights into erythroid development reveal ed through in vitro differentiation of GATA-1- embryonic stem cells. Genes \& Dev. 8: 1184-1197.

Zambrowicz, B.P., A. Imamoto, S. Fiering, L.A. Herzenberg, W.G. Kerr, and P. Soriano. 1997. Disruption of overlapping transcripts in the ROSA $\beta$ geo 26 gene trap strain leads to widespread expression of $\beta$-gal actosi dase in mouse embryos and hematopoietic cells. Proc. Natl Acad. Sci. 94: 3789-3794. 


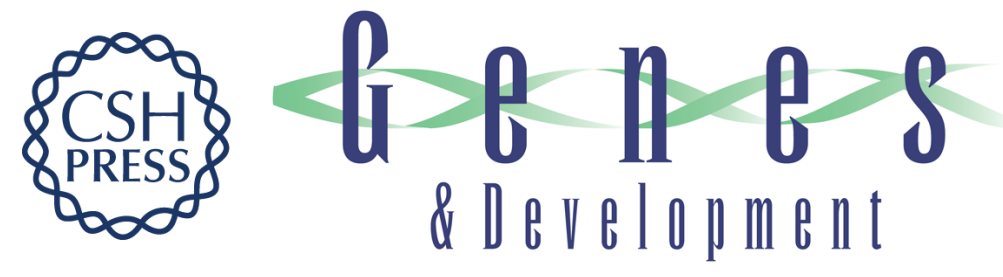

\section{Unsuspected role for the T-cell leukemia protein SCL/tal-1 in vascular development}

Jane E. Visvader, Yuko Fujiwara and Stuart H. Orkin

Genes Dev. 1998, 12:

References This article cites 38 articles, 17 of which can be accessed free at:

http://genesdev.cshlp.org/content/12/4/473.full.html\#ref-list-1

License

Email Alerting
Service $\begin{aligned} & \text { Receive free email alerts when new articles cite this article - sign up in the box at the top } \\ & \text { right corner of the article or click here. }\end{aligned}$

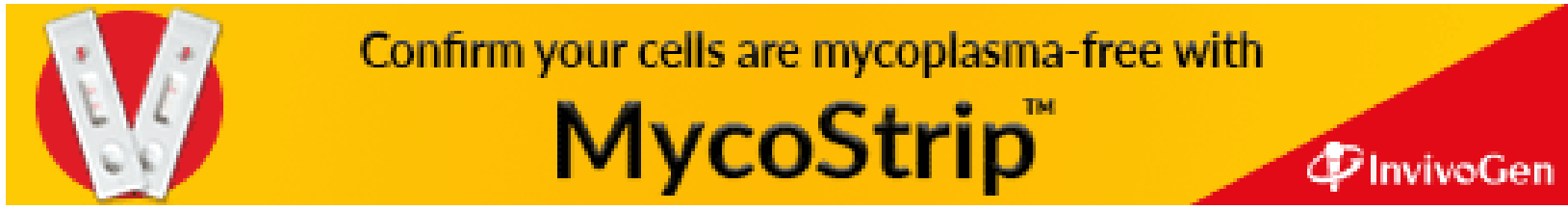

